in virtue of its self-inductance, on establishment of the current through it at each commutation. In this way the two main errors associated with break and self-inductanco are set against ono another, and neutralization is readily effected by experimental test under conditions in which these errors are magnified.

The apparatus is designed for tho accurate and rapid measurement of resistances of approximately one ohm. The rotor has a constant speed of $\mathbf{1 2 . 5}$ rovolutions par second, and the maximum mutual inductance of some $20,000 \mu \mathrm{H}$ permits of fine adjustment within \pm 1 per cent. An accuracy of a few parts in one hundred thousand has been attained.

It is hoped to publish complete details of this investigation elsowhere.

Birkbeck College,

London, E.C.4. Sept. 30.

1 Rosa, Bull. Bur. Standards, 5, 499 (1909). Cf. "Dictionary of Applled Physics", vol. 2, p. 226.

\section{Interfacial Activity of Short-Chain Isomers}

IT is well known that when two long-chain compounds, stereoisomeric with ono another around a double bond, are adsorbed at a surface, they influenco the tension thero to extents which differ according the the effective chain length. Recent experiments by mo have shown that although the thermal agita. tion of short-chain adsorbate molecules at a water-air interface prevents any appreciablo fall in tho surface tension of the solvent, orientation of many small molecules does occur at a water - oil interface. In many cases this is sufficiently marked to roveal interesting differences in interfacial activity between short-chain isomeric compounds, of classes not usually regariled as surface active. Further, theso differences can bo reproduced with an accuracy which enables such measurements to be used as a means of distinguishing between the isomers.

Experiments havo been carried out on two stereoisomeric thio-ether compounds of quadricovalent platinum (kindly supplied by Prof. W. Wardlaw). Tho results shown in Tablo 1 were obtained by methods proviously described ${ }^{1}$, and indicato that while tho trans-compound has no surface activity, the attraction of tho benzene phase for the ethyl groups is sufficient to cause appreciablo orientation of the cis-molecules at the interfuc: $\theta$.

Further evidence for the surface adsorption of short-chain molecules is furnished by tho dibasic acids. The results in Tablo 2 show that, although maleic and fumaric acids are not sufficiently amphipathic to be surface active, the additional methyl group in mesaconic and citraconic acids separates the hydrophobic and hydrophilic centres of the cis-molecule sufficiently for orientation at the interface to occur. Similar well-defined differences can be observed under suitable conditions between cis and trans forms

TABLE 1.

\begin{tabular}{|c|c|}
\hline $\begin{array}{c}\text { Interface } \\
\text { Pure water and : }\end{array}$ & $\begin{array}{c}\text { Interfacial tension } \\
\text { (dynes per cm.) }\end{array}$ \\
\hline $\begin{array}{l}\text { Pure benzene } \\
\text { I per cent solution of trans compound: } \\
\text { (Et) }\end{array}$ & $\begin{array}{l}35 \cdot 41 \\
35 \cdot 30\end{array}$ \\
\hline
\end{tabular}

TAILE 2.

\begin{tabular}{|c|c|}
\hline $\begin{array}{c}\text { Interface } \\
\text { Benzene and : }\end{array}$ & $\begin{array}{c}\text { Interfacial tension } \\
\text { (dynes per cm.) }\end{array}$ \\
\hline $\begin{array}{l}\text { Pure water } \\
\text { 1 per cent solution of maleic acid }\}\end{array}$ & $35 \cdot 41$ \\
1. per "ent solution of"mesaconic äcia (trans) & $35 \cdot 41$ \\
1 " " " citraconic acid (cis) & $\begin{array}{l}35 \cdot 41 \\
23 \cdot 51\end{array}$ \\
\hline
\end{tabular}

of benzaldoxime, and are to be expected with the isomeric diazotates.

Differences in interfacial activity also existing between short-chnin structural isomers such as the toluic acids, cresols. phthalic acids and butyl alcohols are regarded as additional evidence that interfacial orientation does, in fact, occur in many cases where the adsorbate molecules have been previonsly considered too small to display any marked amphipathy.

C. C. Addison.

Chemistry Department,

Harris Institute Technical College, Preston, Lancs.

1 Porney and Addison, Trans. Faraday Soc., 33, 1213 (1937); 34, 350 (1938).

Fibre-Follicle Terminology in the Mammalia

A consideratios of recent investigations ${ }^{1-3}$ into the carly development of the coats and fibres of various breeds of sheop and also of other mammalian types suggests the need for a standard folliclo nomenclature. It has been found that the t:pes within the follicle population and their group arrangement in the skin of the fotus and lamb are among the chief factors which determino what typo of staplo and flece will bo produced. It is obviously necessary, therefore, to agreo upon a consistent terminology if research in this field is to bo intelligibly co-ordinated. The accompanying table indicates tho presont confusion and incorporates our suggestion for a terminology which is simple and, on tho basis of our present knowledge, adequate enough to cover all the jmportant follicle types in the mammalian coat.

It is now well established that the basis of tho folliclo bundlo is usually tho trio group, that is, a group of threo follicles which in the sheep has a special significance in that it produces certain special types of fibres. Other and smaller follicles dovelop later in association with each trio to complete the follicle bundle. First, then, there aro these two clearly defined growth stages, namely: (1) the phase leading to the formation of the trio group; (2) the succeeding or post-trio phase.

In order to make the distinction clear, we suggest that those follicles which are differentiated during the first phase should bo termed primary follicles, and those comprising the second phase, secondary follicles.

All the trio follicles are therefore primary, but in somo types it is possiblo to subdivide tho central members of tho trios into two categories, namely : (1) those which are differentiated early in the first phase; (2) those which aro differentiated later in the first phase.

The earlier and therefore more advanced series of central trio follicles we now term primary $X$ follicles and those which belong to the later stages of the first phase, primary $Y$ follicles. It is important to add, however, that, at least in the Merino breed, not all primary $X$ - or $Y$-follicles become the central members of a trio. Occasionally one remains separate 